\title{
Proteoglycan remodeling is accelerated in women with angina pectoris and diffuse myocardial fibrosis: the iPOWER Study
}

Naja Dam Mygind ( $\square$ ndmygind@dadlnet.dk)

Rigshospitalet https://orcid.org/0000-0001-5592-5148

Signe Holm Nielsen

Nordic Bioscience

Marie Mide Michelsen

Bispebjerg Hospital

Adam Pena

Gentofte Hospital

Daria Frestad Bechsgaard

Hvidovre Hospital

Elena Suhrs

Bispebjerg Hospital

Kira Bang Bove

Bispebjerg Hospital

Federica Genovese

Nordic Bioscience

Henning Bay Nielsen

Sanos Clinics A/S

Morten Karsdal

Nordic Bioscience

Niels Vejlstrup

Rigshospitalet

Eva Prescott

Bispebjerg Hospital

Jens Kastrup

Rigshospitalet

\section{Research}

Keywords: proteoglycan, women, angina pectoris, T1 mapping, cardiac magnetic resonance, coronary microvascular disease, diffuse myocardial fibrosis, extracellular volume, biomarkers, extracellular matrix 
Posted Date: August 18th, 2020

DOI: https://doi.org/10.21203/rs.3.rs-60141/v1

License: (c) (i) This work is licensed under a Creative Commons Attribution 4.0 International License. Read Full License 


\section{Abstract \\ Background}

Women with angina and no obstructive coronary artery disease have an unfavourable prognosis, possibly due to coronary microvascular disease and diffuse myocardial fibrosis. In diffuse myocardial fibrosis myocardial extracellular matrix proteins, including the proteoglycans biglycan and versican are actively remodeled by matrix metalloproteinase. We investigated MMP-mediated degradation of biglycan and versican in women with possible DMF assessed by cardiac magnetic resonance T1 mapping.

\section{Methods}

Seventy-one women with angina pectoris and a coronary angiogram with no significant obstructive coronary artery disease ( $<50 \%$ stenosis) were included. Asymptomatic age-matched women served as controls $(n=32)$. Matrix metalloproteinase 12 generated neo-epitope fragment of versican (VCANM) and MMP-9 generated fragment of biglycan (BGM) were measured in serum by specific competitive enzymelinked immunosorbent assays (ELISAs). T1 mapping was performed by cardiac magnetic resonance with gadolinium $(0.1 \mathrm{mmol} / \mathrm{kg})$ using a look-locker pulse sequencing measuring $\mathrm{T} 1$ and extracellular volume.

\section{Results}

Both BGM and VCANM levels were higher in symptomatic women compared with controls; $31.4 \mathrm{ng} / \mathrm{mL}$ vs. $16.4 \mathrm{ng} / \mathrm{mL}$ ( $p<0.001)$ and $2.1 \mathrm{ng} / \mathrm{mL}$ vs. $1.8 \mathrm{ng} / \mathrm{mL}$ ( $p<0.001)$, respectively. Both BGM and VCANM were moderately correlated to global extracellular volume $\left(r^{2}=0.38, p<0.001\right.$ and $r^{2}=0.26, p=0.015$ respectively).

\section{Conclusion}

Turnover of BGM and VCANM was increased in symptomatic women compared to asymptomatic women and associated to extracellular volume, supporting a link between angina with no obstructive coronary artery disease and fibrotic cardiac remodeling. The examined biomarkers may prove to be suitable for monitoring active extracellular matrix remodeling.

\section{Introduction}

Less than half of women with angina pectoris referred for an invasive coronary angiography (CAG) have significant obstructive coronary artery disease (CAD) (1). This remains a challenge, as angina pectoris in spite of the lack of obstructive CAD is associated with increased morbidity and mortality (1). A possible cause of symptoms may be repeated transient ischemia caused by coronary microvascular dysfunction (CMD) $(1,2)$. CMD is a strong marker of adverse prognosis and studies indicate that CMD is present in up 
to $47 \%$ of subjects with angina and no obstructive CAD (3-6). It has been suggested that CMD is linked to impaired diastolic function and the development of heart failure with reduced ejection fraction (7).

The cardiac extracellular matrix (ECM) is a dynamic structure, where the balance of protein formation and degradation is tightly controlled by growth factors and proteases (8). An important class of ECM components is the proteoglycan family, which are implicated in regulation and organization of the collagen fibrils in cardiac tissue (9). The small leucine-rich proteoglycan biglycan (BGM) interacts with collagens to promote their stability in the fibrotic scar following myocardial infarction $(10,11)$. The large proteoglycan versican (VCANM) represents the major cardiac hyalectan necessary for normal cardiac and vascular development (12). VCANM is known to mediate inflammatory cell-to-cell, and cell-to-matrix interactions (13). Chronic low-grade cardiac ischemia promotes active cardiac ECM remodeling (14). We therefore hypothesized that repeated episodes of ischemia induced by CMD will lead to higher levels of these two major ECM components in women with angina and no obstructive CAD suspected of CMD.

The aim of this study was to compare serum levels of the two neo-epitope biomarkers of VCANM and BGM in women with angina pectoris and no obstructive CAD disease and in asymptomatic women. Furthermore, we wanted to investigate the association of these biomarkers to cardiac magnetic resonance (CMR) T1 mapping; a measure of diffuse myocardial fibrosis (DMF). T1 mapping has been validated against histological assessment of fibrosis in myocardial biopsies $(15,20-23)$.

\section{Methods}

\section{Study population}

The present study is a sub-study of the iPOWER study cohort (ImProve diagnOsis and treatment of Women with angina pEctoris and micRovessel disease) that were included in the period May 2012 to May 2014 (16). In short, women with angina-like chest pain and no significant obstructive CAD assessed by diagnostic invasive CAG, a left ventricular ejection fraction $>45 \%$ and no significant valvulopathy were included. All participants had serum collected and stored at $-80^{\circ} \mathrm{C}$ until analysis. A control group of 32 asymptomatic age-matched women were included from the Copenhagen City Heart Study, a community based population study (17). Serum was collected from all 32 controls between June and September 2015. Asymptomatic women did not undergo CMR.

\section{Biomarker investigation and cardiac magnetic resonance}

Biomarkers of specific matrix metalloproteinase (MMP)-generated fragments of BGM and VCANM were measured by competitive enzyme-linked immunosorbent assays (ELISAs) developed by Nordic Bioscience (Herlev, Denmark). Levels were measured in serum of both the women with angina and controls. The ELISAs were performed as previously described $(18,19)$. 
Cardiac magnetic resonance T1 mapping was performed on a MAGNETOM Avanto 1.5-Tesla scanner (Siemens, Erlangen, Germany) using the modified look-locker inversion recovery technique (MOLLI) (24). CMR analysis was performed using the commercially available software CVI42 version 5.1.1 (Circle Cardiovascular Imaging Inc., Calgary, Canada) reporting T1 values as well as extracellular volume (ECV) indicating the percentage of the myocardium not taken up by cells and thus DMF (23).

\section{Statistical analysis}

Differences between patient demographics and biomarker levels of BGM and VCANM in asymptomatic women and symptomatic women were determined by a non-parametric Wilcoxon-Mann-Whitney $t$-test. Participants were divided into tertiles according to BGM and VCANM values and associations with CMR variables were determied by the Kruskal-Wallis test. Correlations between biomarkers and clinical parameters were calculated using Spearman's rho.

Furthermore, to quantify the added diagnostic value of BGM and VCANM to separate the symptomatic women from the asymptomatic women in a model including other risk factors, we calculated ROC curves and applied C-statistics to compare the AUC for the model including the conventional cardiovascular risk factors age, systolic blood pressure, diastolic blood pressure, hypertension and hyperlipidemia ("Base model") and the AUC for the model including conventional cardiovascular risk factors plus BGM ("Base model + BGM") and VCANM ("Base model + VCANM"), respectively. As C-statistics often do not significantly improve even after addition of powerful diagnostic parameters, we also calculated the Net Reclassification Improvement (NRI) index (25) in order to demonstrate the potential usefulness of adding a biomarker to a conventional model of risk factors. The NRI index is defined as the increase in discrimination slope when adding BGM or VCANM, respectively, to conventional risk factors (Model 2) divided by the discrimination slope of the model only consisting of the conventional risk factors (Model 1) minus 1 . Statistically significance threshold was set at $p<0.05$. All statistical analyses were performed using GraphPad Prism version 7 (GraphPad Software, San Diego, CA, USA).

\section{Results}

\section{Demographics}

\section{Biglycan and versican turnover}

Serum levels of BGM and VCANM were significantly higher in the symptomatic women compared to controls (91.5\% and $85.7 \%$, respectively, both $p<0.001$, Figure $1 \mathrm{~A}-1 \mathrm{~B}$ ). As shown in Figure $2 \mathrm{~A}, \mathrm{BGM}$ was able to discriminate between the symptomatic women and the asymptomatic women with an AUC of 0.81 (95\% confidence interval (Cl) 0.72-0.89), while VCANM gave an AUC of 0.77 (95\% Cl 0.66-0.87). The model including the conventional risk factors (age, systolic and diastolic blood pressure, hypertension and hyperlipidemia) yielded an area under the curve (AUC) of $0.94(95 \% \mathrm{Cl} 0.87-0.98, \mathrm{p}<0.0001)$ and the 
addition of BGM or VCANM did not provide a significant improvement in C-statistics ( $p=0.316$ and $p=0.108$, respectively). However, the addition of BGM and VCANM significantly improved the NRI index for diagnosis of patients with angina compared to asymptomatic women ( $p=0.01$ and $p=0.002$, respectively).

\section{Associations between the biomarkers, clinical parameters and CMR measures of DMF}

BGM was correlated with hypertension ( $r=0.35, p<0.001$, hypercholesterolemia $(r=0.25, p=0.013)$, current smoking $(r=0.25, p=0.013)$, statin treatment $(r=0.30, p=0.002)$ systolic and diastolic blood pressure $(r=0.32, p=0.002$ and $r=50, p<0.001$, respectively). VCANM was correlated with systolic and diastolic blood pressure $(r=0.29, p=0.004$ and $r=0.40, p<0.001$, respectively) and levels of triglycerides $(r=0.25$, $\mathrm{p}=0.012$ ). For the entire myocardium mean native T1 was $1023 \mathrm{~ms}$ and mean ECV was $33.7 \%$. Both BGM and VCANM showed a moderate correlation to ECV ( $r=0.38, p<0.001$ and $r=0.26, p=0.015$ respectively). No association between the biomarkers and native T1 was found.

\section{Discussion}

To our knowledge, this is the first study to use neo-epitope specific biomarkers to describe proteoglycan remodeling in the myocardium. Our main findings were as follows: 1) Levels of BGM and VCANM were elevated in women with angina pectoris and no obstructive CAD compared to asymptomatic women; 2 ) There was no significant association between levels of BGM and VCANM and native T1, but a moderate though significant association between both BGM and VCANM and global ECV; 3) BGM and VCANM were able to separate asymptomatic women from angina patients and improved the NRI index compared to conventional risk factors indicating that both markers could separate patients with angina from asymptomatic women with a high diagnostic accuracy. The results suggest that women with angina pectoris and no obstructive CAD have a higher ECM remodeling rate compared to age-matched asymptomatic women and that this may be part of the pathophysiology.

The iPOWER study aims at investigating novel non-invasive diagnostic techniques to identify CMD in women with angina-like chest pain and no obstructive CAD (16) and in a subgroup the association between CMD and DMF assessed by CMR (24). This current sub-study, although of limited size, has identified proteoglycan biomarkers that may reflect disease activity occurring in women with angina pectoris and no obstructive CAD (26), who we know have a poorer prognosis compared to asymptomatic women (1). The underlying mechanism behind the poorer prognosis may be related to the presence of $\mathrm{CMD}$ that causes transient ischemia. Upon transient limitation in coronary oxygen supply the ECM becomes actively remodeled, leading to DMF, stiffness of the left ventricle and potentially heart failure. Proteoglycans are important ECM components, implicated in regulation and organization of the collagen fibrils in the cardiac tissue (9).

The cardiac ECM is necessary to preserve the structural ventricular integrity however, when ECM proteins accumulate causing focal and diffuse fibrosis, they may be detrimental to cardiac function (27-30). In 
DMF, the normal balance between tissue formation and degradation is shifted, leading to both increased formation and degradation of ECM proteins. Collagens are the major components of the cardiac ECM, and act as substrate for several MMPs. Excessive collagen deposition may results in a stiff and noncompliant left ventricle, while insufficient collagen deposition may cause left ventricular thinning and dilation (31).

In this study, the circulating proteoglycan biomarkers were associated with DMF assessed by ECV but not with native T1 mapping, perhaps indicating that these biomarkers are an early sign of pathology that CMR is not able to detect. We speculate that cardiac magnetic resonance T1 mapping may be a less sensitive method to detect DMF compared to proteoglycan biomarkers in this angina-population, in contrast to populations with more advanced CAD where T1 mapping is able to distinguish patients from healthy asymptomatic women (32). Only the T1 mapping variable ECV was associated with proteoglycan and not native T1. Native (pre-contrast) T1 varies depending on water content in the myocardium whereas the T1 mapping variable ECV is a quantitative estimate of the part of the myocardium not taken up by cells derived from native and post-contrast T1 times from the myocardium and the blood, as well as the blood contrast volume (1-hematocrit) (21). Hence, ECV may be a more complete CMR measure of DMF. Another study from our group found that only the CMR parameter ECV, and not native T1, was associated with $\mathrm{C} 5 \mathrm{M}$, a collagen type $\mathrm{V}$ degradation biomarker indicating active collagen remodeling (33). ECV can potentially divide the myocardium into its cellular and interstitial components and its prognostic value has been reported in the literature. (34). This may suggest that both biomarkers of ECM turnover and CMR can be used as non-invasive methods to assess the active remodeling caused by transient ischemia in women with potential CMD. These preliminary findings should however be validated in larger clinical settings and in a population with a greater spectrum of disease.

\section{Strengths And Limitations}

Participating women were consecutively included and examined systematically, and all had a clinical invasive CAG ruling out obstructive CAD. The study population was rather small, and we cannot exclude that the variation in T1 values and biomarker levels were too small to identify possible associations. However, the study size is reasonable for an imaging study and the burden of cardiovascular risk factors was high, indicating that we included women at risk. The asymptomatic women did not undergo CMR examination due to logistics. Future studies would benefit from inclusion of a larger patient group with more severe DMF along with a longitudinal follow-up, to evaluate the proteoglycan markers over time. Another limitation involves the organ specificity of the investigated biomarkers, as these proteoglycans are present in soft tissues throughout the body and therefore cannot be qualified as entirely myocardiumspecific (35).

\section{Conclusion}

In women with angina pectoris and no obstructive CAD turnover of the proteoglycan biomarkers biglycan and versican was increased compared with asymptomatic women and associated to ECV a CMR 
measure of DMF. These data support a link between angina with no obstructive CAD and fibrotic cardiac remodeling which may potentially lead to development of heart failure with preserved ejection fraction. Pending further studies, the examined biomarkers may be useful for monitoring active ECM remodeling.

\section{Abbreviations}

BGM: biglycan

CAD: coronary artery disease

CAG: coronary angiography

CMD: coronary microvascular dysfunction

CMR: cardiac magnetic resonance

DMF: diffuse myocardial fibrosis

ECM: extracellular matrix

ELISA: enzyme-linked immunosorbent assays

iPOWER: ImProve diagnOsis and treatment of Women with angina pEctoris and micRovessel disease

MOLLI: modified look-locker inversion recovery technique

NRI: Net Reclassification Improvement

VCANM: versican

\section{Declarations}

\section{Ethics}

This study was performed in accordance with the Helsinki Declaration and was approved by the Danish Regional Committee on Biomedical Research Ethics (H-3-2012-005). All participants have given written informed consent upon oral and written information.

\section{Consent for publication}

Not applicable

\section{Avaliability}

The data is available from the authors upon personel request 


\section{Competing interests}

FG and MK are full-time employees at Nordic Bioscience and HBN is full-time employee at ProScion. FG and MK hold stocks at Nordic Bioscience. All other authors have no conflict of interest.

\section{Funding}

This work was supported by The Danish Heart Foundation (grant number: 11-10-R87-B-A3628-22678), the Danish Research Fund (Den Danske Forskningsfond) and by University of Copenhagen.

\section{Author contributions}

NDM designed the study, included patients and participants, performed the CMR examinations and made the manuscript draft ready for submission

SHN designed the study, performed biomarker analyses and made the manuscript draft ready for submission

MMM helped in design of the study, included patients and participants. Revieved the draft critically before submission

AP helped in design of the study, included patients and participants. Revieved the draft critically before submission

ES helped in design of the study, included patients and participants. Revieved the draft critically before submission

DFB helped in design of the study, included patients and participants. Revieved the draft critically before submission

KB helped in design of the study, included patients and participants. Revieved the draft critically before submission

FG helped in the design of the study with focus on biomarkers. Revieved the draft critically before submission

HBN helped in the design of the study with focus on biomarkers. Revieved the draft critically before submission

MK helped in the design of the study with focus on biomarkers. Revieved the draft critically before submission

NV helped in the design of the study with focus on cardiac magnetic resonance. Revieved the draft critically before submission 
EP designed the study. Revieved the draft critically before submission

JK designed the study. Revieved the draft critically before submission

\section{Acknowledgements}

The authors would like to thank the Danish Heart Foundation, the University of Copenhagen, The Innovation Foundation and the Danish Research Fund (Den Danske Forskningsfond) for financial support and all collaborators in the iPOWER group. We also thank the Department of Cardiology at Bispebjerg Hospital and the Department of Radiology at Rigshospitalet where the examinations have taken place. A special thanks to the CMR technicians Birte Kjærulff, Jesper Kromann, Andrija Srkoc and Torben Vaaben for assisting in scanning the participants. Finally, we thank all the participating women in iPOWER for their time and willingness to contribute to the research.

\section{References}

1. Jespersen L, Hvelplund A, Abildstrøm SZ, Pedersen F, Galatius S, Madsen JK, et al. Stable angina pectoris with no obstructive coronary artery disease is associated with increased risks of major adverse cardiovascular events. Eur Heart J [Internet]. 2012 Mar;33(6):734-44. Available from: http://www.ncbi.nlm.nih.gov/pubmed/21911339

2. Jespersen L, Abildstrøm SZ, Hvelplund A, Prescott E. Persistent angina: highly prevalent and associated with long-term anxiety, depression, low physical functioning, and quality of life in stable angina pectoris. Clin Res Cardiol [Internet]. 2013 Aug;102(8):571-81. Available from: http://www.ncbi.nlm.nih.gov/pubmed/23636227

3. Murthy VL, Naya M, Taqueti VR, Foster CR, Gaber M, Hainer J, et al. Effects of sex on coronary microvascular dysfunction and cardiac outcomes. Circulation [Internet]. 2014 Jun 17;129(24):251827. Available from: http://www.ncbi.nlm.nih.gov/pubmed/24787469

4. Sicari R, Rigo F, Cortigiani L, Gherardi S, Galderisi M, Picano E. Additive prognostic value of coronary flow reserve in patients with chest pain syndrome and normal or near-normal coronary arteries. Am J Cardiol [Internet]. 2009 Mar 1;103(5):626-31. Available from: http://www.ncbi.nlm.nih.gov/pubmed/19231324

5. Reis SE, Holubkov R, Smith AJC, Kelsey SF, Sharaf BL, Reichek N, et al. Coronary microvascular dysfunction is highly prevalent in women with chest pain in the absence of coronary artery disease: Results from the NHLBI WISE study. Am Heart J. 2001;141(5):735-41.

6. Brainin $P$, Frestad $D$, Prescott $E$. The prognostic value of coronary endothelial and microvascular dysfunction in subjects with normal or non-obstructive coronary artery disease: A systematic review and meta-analysis. Int J Cardiol [Internet]. 2018;254:1-9. Available from: http://www.ncbi.nlm.nih.gov/pubmed/29407076 
7. Bairey Merz CN, Pepine CJ, Walsh MN, Fleg JL. Ischemia and No Obstructive Coronary Artery Disease (INOCA): Developing Evidence-Based Therapies and Research Agenda for the Next Decade. Circulation [Internet]. 2017 Mar 14;135(11):1075-92. Available from: http://www.ncbi.nlm.nih.gov/pubmed/28289007

8. Järveläinen H, Sainio A, Koulu M, Wight TN, Penttinen R. Extracellular matrix molecules: potential targets in pharmacotherapy. Pharmacol Rev [Internet]. 2009 Jun;61(2):198-223. Available from: http://www.ncbi.nlm.nih.gov/pubmed/19549927

9. Schaefer L, Schaefer RM. Proteoglycans: from structural compounds to signaling molecules. Cell Tissue Res [Internet]. 2010 Jan;339(1):237-46. Available from:

http://www.ncbi.nlm.nih.gov/pubmed/19513755

10. Beetz N, Rommel C, Schnick T, Neumann E, Lother A, Monroy-Ordonez EB, et al. Ablation of biglycan attenuates cardiac hypertrophy and fibrosis after left ventricular pressure overload. J Mol Cell Cardiol [Internet]. 2016 Dec;101:145-55. Available from: http://www.ncbi.nIm.nih.gov/pubmed/27789290

11. lozzo R V, Karamanos N. Proteoglycans in health and disease: emerging concepts and future directions. FEBS J [Internet]. 2010 Oct;277(19):3863. Available from:

http://www.ncbi.nlm.nih.gov/pubmed/20812984

12. Kern CB, Wessels A, McGarity J, Dixon LJ, Alston E, Argraves WS, et al. Reduced versican cleavage due to Adamts9 haploinsufficiency is associated with cardiac and aortic anomalies. Matrix Biol [Internet]. 2010 May;29(4):304-16. Available from: http://www.ncbi.nlm.nih.gov/pubmed/20096780

13. Toeda K, Nakamura K, Hirohata S, Hatipoglu OF, Demircan K, Yamawaki H, et al. Versican is induced in infiltrating monocytes in myocardial infarction. Mol Cell Biochem [Internet]. 2005 Dec;280(12):47-56. Available from: http://www.ncbi.nlm.nih.gov/pubmed/16311904

14. Frangogiannis NG. The extracellular matrix in myocardial injury, repair, and remodeling. J Clin Invest [Internet]. 2017 May 1;127(5):1600-12. Available from: http://www.ncbi.nlm.nih.gov/pubmed/28459429

15. Flett AS, Hayward MP, Ashworth MT, Hansen MS, Taylor AM, Elliott PM, et al. Equilibrium contrast cardiovascular magnetic resonance for the measurement of diffuse myocardial fibrosis: Preliminary validation in humans. Circulation. 2010;122(2):138-44.

16. Prescott E, Abildstrøm SZ, Aziz A, Merz NB, Gustafsson I, Halcox J, et al. Improving diagnosis and treatment of women with angina pectoris and microvascular disease: The iPOWER study design and rationale. Am Heart J. 2014;167(4).

17. Schnohr P, Jensen G, Nyboe J, Eybjaerg Hansen A. [The Copenhagen City Heart Study. A prospective cardiovascular population study of 20,000 men and women]. Ugeskr Laeger [Internet]. 1977 Aug 8;139(32):1921-3. Available from: http://www.ncbi.nlm.nih.gov/pubmed/906112

18. Genovese F, Barascuk N, Larsen L, Larsen MR, Nawrocki A, Li Y, et al. Biglycan fragmentation in pathologies associated with extracellular matrix remodeling by matrix metalloproteinases.

Fibrogenesis Tissue Repair [Internet]. 2013 May 1;6(1):9. Available from:

http://www.ncbi.nlm.nih.gov/pubmed/23635022 
19. Barascuk N, Genovese F, Larsen L, Byrjalsen I, Zheng Q, Sun S, et al. A MMP derived versican neoepitope is elevated in plasma from patients with atherosclerotic heart disease. Int J Clin Exp Med. 2013;6(3):174-84.

20. Higgins DM, Ridgway JP, Radjenovic A, Sivananthan UM, Smith MA. T1 measurement using a short acquisition period for quantitative cardiac applications. Med Phys [Internet]. 2005 Jun;32(6):173846. Available from: http://www.ncbi.nlm.nih.gov/pubmed/16013731

21. Moon JC, Messroghli DR, Kellman P, Piechnik SK, Robson MD, Ugander M, et al. Myocardial T1 mapping and extracellular volume quantification: a Society for Cardiovascular Magnetic Resonance (SCMR) and CMR Working Group of the European Society of Cardiology consensus statement. J Cardiovasc Magn Reson [Internet]. 2013;15(1):92. Available from: http://jcmronline.biomedcentral.com/articles/10.1186/1532-429X-15-92

22. Bull S, White SK, Piechnik SK, Flett AS, Ferreira VM, Loudon M, et al. Human non-contrast T1 values and correlation with histology in diffuse fibrosis. Heart [Internet]. 2013;99(13):932-7. Available from: http://heart.bmj.com/lookup/doi/10.1136/heartjnl-2012-303052

23. Miller CA, Naish JH, Bishop P, Coutts G, Clark D, Zhao S, et al. Comprehensive validation of cardiovascular magnetic resonance techniques for the assessment of myocardial extracellular volume. Circ Cardiovasc Imaging. 2013;6(3):373-83.

24. Mygind ND, Michelsen MM, Pena A, Qayyum AA, Frestad D, Christensen TE, et al. Coronary microvascular function and myocardial fibrosis in women with angina pectoris and no obstructive coronary artery disease: the iPOWER study. J Cardiovasc Magn Reson. 2016;18(1).

25. Pencina MJ, D’Agostino RB, Vasan RS. Statistical methods for assessment of added usefulness of new biomarkers. Clin Chem Lab Med [Internet]. 2010 Dec;48(12):1703-11. Available from: http://www.ncbi.nlm.nih.gov/pubmed/20716010

26. Ntusi NAB, Piechnik SK, Francis JM, Ferreira VM, Matthews PM, Robson MD, et al. Diffuse Myocardial Fibrosis and Inflammation in Rheumatoid Arthritis: Insights From CMR T1 Mapping. JACC Cardiovasc Imaging [Internet]. 2015 May;8(5):526-36. Available from: http://www.ncbi.nlm.nih.gov/pubmed/25890584

27. Kong P, Christia P, Frangogiannis NG. The pathogenesis of cardiac fibrosis. Cell Mol Life Sci [Internet]. 2014 Feb;71(4):549-74. Available from: http://www.ncbi.nlm.nih.gov/pubmed/23649149

28. Frustaci A, Kajstura J, Chimenti C, Jakoniuk I, Leri A, Maseri A, et al. Myocardial cell death in human diabetes. Circ Res [Internet]. 2000 Dec 8;87(12):1123-32. Available from: http://www.ncbi.nlm.nih.gov/pubmed/11110769

29. Pardo Mindán FJ, Panizo A. Alterations in the extracellular matrix of the myocardium in essential hypertension. Eur Heart J [Internet]. 1993 Nov;14 Suppl J:12-4. Available from: http://www.ncbi.nlm.nih.gov/pubmed/8281955

30. Schwartzkopff B, Motz W, Frenzel H, Vogt M, Knauer S, Strauer BE. Structural and functional alterations of the intramyocardial coronary arterioles in patients with arterial hypertension. 
Circulation [Internet]. 1993 Sep;88(3):993-1003. Available from:

http://www.ncbi.nlm.nih.gov/pubmed/8353927

31. Lindsey ML, lyer RP, Zamilpa R, Yabluchanskiy A, DeLeon-Pennell KY, Hall ME, et al. A Novel Collagen Matricryptin Reduces Left Ventricular Dilation Post-Myocardial Infarction by Promoting Scar Formation and Angiogenesis. J Am Coll Cardiol [Internet]. 2015 Sep 22;66(12):1364-74. Available from: http://www.ncbi.nlm.nih.gov/pubmed/26383724

32. Sado DM, Flett AS, Banypersad SM, White SK, Maestrini V, Quarta G, et al. Cardiovascular magnetic resonance measurement of myocardial extracellular volume in health and disease. Heart [Internet]. 2012;98(19):1436-41. Available from: http://heart.bmj.com/lookup/doi/10.1136/heartjnl-2012302346

33. Nielsen SH, Mygind ND, Michelsen MM, Bechsgaard DF, Suhrs HE, Genovese F, et al. Accelerated collagen turnover in women with angina pectoris without obstructive coronary artery disease: An iPOWER substudy. Eur J Prev Cardiol. 2018;25(7).

34. Wong TC, Piehler K, Meier CG, Testa SM, Klock AM, Aneizi AA, et al. Association between extracellular matrix expansion quantified by cardiovascular magnetic resonance and short-term mortality. Circulation [Internet]. 2012 Sep 4;126(10):1206-16. Available from: http://www.ncbi.nlm.nih.gov/pubmed/22851543

35. Karsdal MA, Henriksen K, Leeming DJ, Woodworth T, Vassiliadis E, Bay-Jensen A-C. Novel combinations of Post-Translational Modification (PTM) neo-epitopes provide tissue-specific biochemical markers--are they the cause or the consequence of the disease? Clin Biochem [Internet]. 2010 Jul;43(10-11):793-804. Available from: http://www.ncbi.nlm.nih.gov/pubmed/20381482

\section{Tables}

Table 1. Characteristics of symptomatic women and asymptomatic women 


\begin{tabular}{|c|c|c|c|}
\hline Variable & $\begin{array}{l}\text { Asymptomatic women, } \\
\mathrm{n}=32\end{array}$ & $\begin{array}{l}\text { Symptomatic women, } \\
\mathrm{n}=71\end{array}$ & $p$-value \\
\hline Age (years), mean $\pm S D$ & $63 \pm 11$ & $62 \pm 8$ & 0.680 \\
\hline Hypertension, n (\%) & 7 (21.9\%) & $40(56.3 \%)$ & 0.001 \\
\hline Hyperlipidemia, n (\%) & $4(12.5 \%)$ & $45(63.4 \%)$ & $<0.0001$ \\
\hline $\begin{array}{l}\text { Family history of ischemic heart } \\
\text { disease, } \mathrm{n}(\%)\end{array}$ & $8(25.0 \%)$ & $39(55.7 \%)$ & 0.004 \\
\hline Smoking (current), n (\%) & $5(15.6 \%)$ & $17(23.9 \%)$ & 0.345 \\
\hline $\begin{array}{l}\text { Peripheral vascular disease } \\
\text { (claudicatio), } \mathrm{n}(\%)\end{array}$ & $2(6.3 \%)$ & $3(4.2 \%)$ & 0.662 \\
\hline Atheromatosis at CAG* $\mathrm{n}(\%)$ & $\mathrm{N} / \mathrm{A}$ & $27(38.0 \%)$ & - \\
\hline Post-menopausal, n (\%) & $27(84.4 \%)$ & $62(89.9 \%)$ & 0,456 \\
\hline \multicolumn{4}{|l|}{ Clinical assessment } \\
\hline $\begin{array}{l}\mathrm{BMI}\left(\mathrm{kg} / \mathrm{m}^{2}\right), \text { mean } \pm \mathrm{SD} \\
\text { Systolic blood pressure }(\mathrm{mmHg}) \\
\text { mean } \pm \text { SD } \\
\text { Diastolic blood pressure }(\mathrm{mmHg}) \\
\text { mean } \pm \text { SD } \\
\text { Heart rate at rest (beats } / \mathrm{min}) \text {, mean } \pm \\
\mathrm{SD} \\
\text { Left ventricular mass index }{ }^{\star} \text {, mean } \pm \\
\mathrm{SD}\end{array}$ & $\begin{array}{l}24.5 \pm 3.8 \\
119 \pm 16 \\
60 \pm 9 \\
72 \pm 11 \\
\text { N/A }\end{array}$ & $\begin{array}{l}25.4 \pm 4.4 \\
147 \pm 24 \\
84 \pm 15 \\
65 \pm 10 \\
60.1 \pm 5.7\end{array}$ & $\begin{array}{l}0.303 \\
<0.0001 \\
<0.0001 \\
0.003 \\
-\end{array}$ \\
\hline \multicolumn{4}{|l|}{ Laboratory tests } \\
\hline $\begin{array}{l}\text { Total cholesterol }(\mathrm{mmol} / \mathrm{L}) \text {, mean } \pm \\
\text { SD } \\
\text { HDL cholesterol }(\mathrm{mmol} / \mathrm{L}) \text {, mean } \pm \\
\text { SD } \\
\text { LDL cholesterol }(\mathrm{mmol} / \mathrm{L}) \text {, mean } \pm \\
\text { SD } \\
\text { Triglycerides (mmol/L), mean } \pm \mathrm{SD}\end{array}$ & $\begin{array}{l}5.4 \pm 0.8 \\
2.0 \pm 0.5 \\
2.9 \pm 0.8 \\
0.9 \pm 0.4\end{array}$ & $\begin{array}{l}4.9 \pm 1.0 \\
1.6 \pm 0.7 \\
2.8 \pm 1.0 \\
1.2 \pm 0.7\end{array}$ & $\begin{array}{l}0.017 \\
0.012 \\
0.452 \\
0.035\end{array}$ \\
\hline \multicolumn{4}{|l|}{ Treatment } \\
\hline $\begin{array}{l}\text { Statin, } \mathrm{n}(\%) \\
\text { Beta blockers, } \mathrm{n}(\%) \\
\text { Calcium antagonist, } \mathrm{n}(\%) \\
\text { ACE inhibitor, } \mathrm{n}(\%) \\
\text { Aspirin, } \mathrm{n}(\%) \\
\text { ANGII receptor antagonist, n (\%) }\end{array}$ & $\begin{array}{l}3(9.4 \%) \\
0(0 \%) \\
2(6.3 \%) \\
5(15.6 \%) \\
1(3.1 \%) \\
2(6.3 \%)\end{array}$ & $\begin{array}{l}36(50.7 \%) \\
23(32.4 \%) \\
20(28.6 \%) \\
12(17.4 \%) \\
36(50.8 \%) \\
12(17.4 \%)\end{array}$ & $\begin{array}{l}<0.0001 \\
- \\
0.011 \\
0.827 \\
<0.0001 \\
0.134\end{array}$ \\
\hline
\end{tabular}

SD: standard deviation; CAG: coronary angiography; BMI: body mass index; HDL: High-density lipoprotein cholesterol; LDL: Low-density lipoprotein cholesterol; ACE: angiotensin converting enzyme; ANGII: angiotensin Il; ASA: acetylsalicylic acid treatment. *Left ventricular Mass Index and atherosclerosis at CAG is only available for the symptomatic group $(n=71)$. 
A

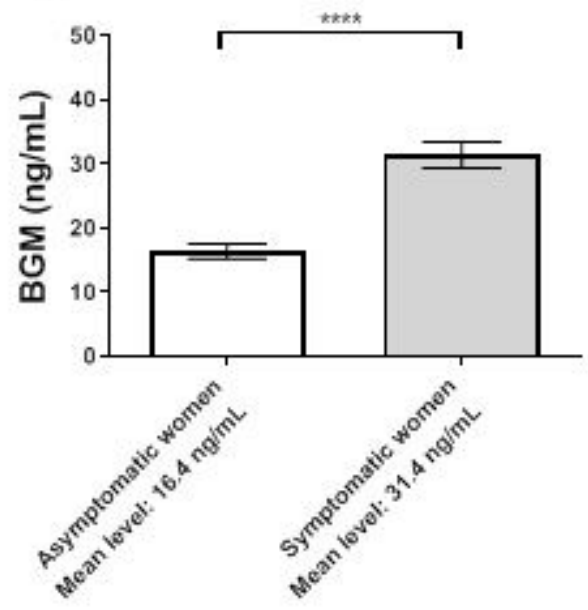

B

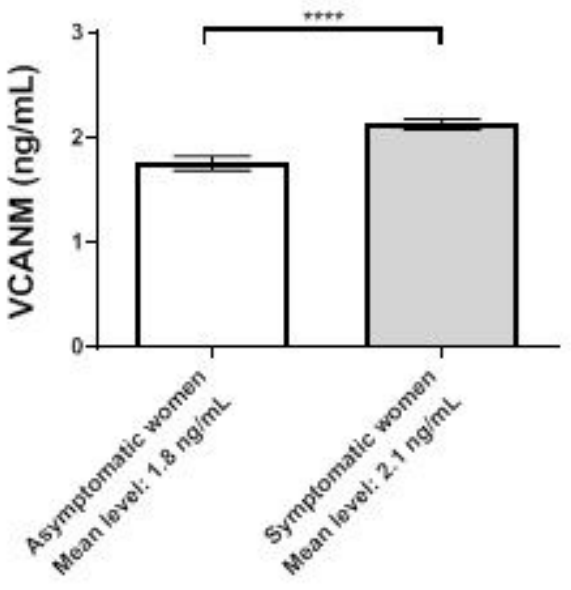

\section{Figure 1}

Levels of the two biomarkers of fibrotic remodelling in serum of asymptomatic women $(n=32)$ and symptomatic women with angina pectoris ( $n=71)$. A) Serum levels of MMP-mediated biglycan (BGM); B) Serum levels of MMP-mediated versican (VCANM). Statistical differences were calculated using a nonparametric Wilcoxon-Mann-Whitney t-test. Data are presented as mean \pm SEM. ${ }^{\star \star \star *}$ : $p<0.0001$.

A

Asymptomatic women vs. Symptomatic women BGM

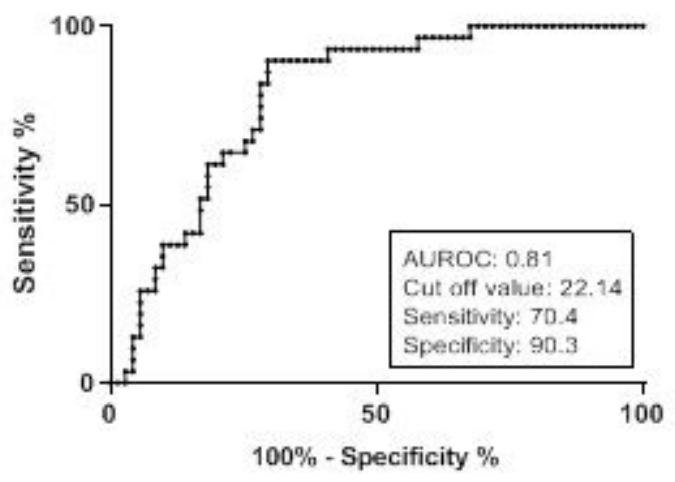

B

Asymptomatic women vs. Symptomatic women VCANM

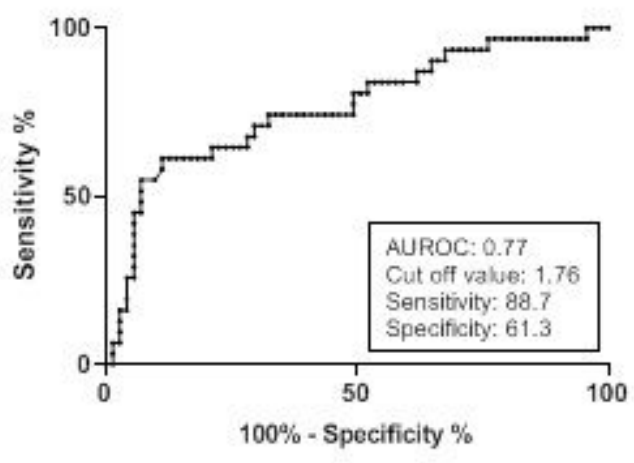

Figure 2

Results of ROC analysis to evaluate the ability of BGM (A) and VCANM (B) to discriminate between symptomatic women and asymptomatic women. 